\title{
Leptospirosis: re-emerging or re-discovered disease?
}

Leptospirosis is a ubiquitous zoonotic disease, the incidence of which is uncertain, but which is certainly underestimated [1]. It is now regarded as one of the emerging infections [2], but the wide spectrum of symptoms contributes greatly to underdiagnosis. Interest has been stimulated by recent outbreaks in Central America, and by the appearance of clusters of cases with unexpected symptoms. In Nicaragua, a haemorrhagic pneumonitis was predominant [3], while in India there have been large outbreaks of leptospirosis associated with uveitis [4].

The resurgence of attention to leptospirosis in tropical countries has resulted, at least in part, from the excess rainfall associated with the El Niño southern oscillation weather phenomenon. Moreover, in temperate climates, leptospirosis has also been 're-discovered' as a cause of illness in poor urban dwellers [5], and an outbreak among triathletes in Illinois illustrates the role of changing human behaviour in the risks of exposure via the natural environment [6]. Leptospirosis should be considered in the differential diagnosis of the febrile returning traveller [7], particularly in those partaking in 'adventure tourism' [8]. Several cases have been reported in tourists returning from tropical countries, in whom haemorrhagic fevers have been suspected [9].

There are important differences in the epidemiology of the disease in temperate and tropical regions. In Europe, North America and other developed regions, the groups at risk are largely those involved in animal husbandry (farmers, veterinarians) and those whose leisure activities expose them to immersion in water. In tropical climates the entire population can be at risk of exposure through their everyday activities. Flooding following excessive rainfall greatly increases this universal risk of exposure. Conversely, reduced rainfall will be expected to lead to a reduction in cases.

The range of serovars common in temperate regions (icterohaemorrhagiae, hardjo, pomona, bratislava, canicola) is much smaller than that found in tropical countries. New serovars will continue to be described from regions in which research has begun only recently $[10]$.

While the understanding of the epidemiology of leptospirosis in a region depends upon the ability to isolate the serovars involved and identify the reservoir animals, diagnosis still depends mainly upon serology, because the isolation and characterisation of leptospires require significant expertise and can take months to complete. The microscopic agglutination test remains the definitive serological assay, not least because it can yield information on the presumptive infecting serogroup. However, problems abound: paired sera are required for certain diagnosis; large numbers of live antigen serovars must be maintained; reproducibility between laboratories is inconsistent; it remains impossible to identify the infecting serovar by serology; and the definition of a probable case based upon the titre in a single specimen depends upon the population from which the patient is drawn. Titres of 200,400 or 800 are commonly used to indicate infection in different regions. However, even a high threshold titre of 800 may persist for several months [11], and in regions in which leptospirosis is endemic, there is a danger that other febrile diseases may be misdiagnosed as presumptive leptospirosis, if the microscopic agglutination test is the only serological test applied.

Other tests have been used for rapid, presumptive diagnosis. In the USA, the indirect haemagglutination test has for many years been the only diagnostic assay approved by the Food and Drug Administration, while in Europe, Australia and other regions, variations on the ELISA theme have been widely used for the detection of IgM. Several rapid dipstick assays have been developed and further evaluations are in progress.

Molecular diagnosis by the PCR, while more sensitive and much more rapid than culture, is less sensitive than serological diagnosis [12]. Much work remains to be done to optimise this approach to diagnosis. In fatal cases, diagnosis by immunohistochemistry is both specific and more rapid than culture, and gave the first indication of the leptospiral aetiology of the outbreak in Nicaragua [13].

Early diagnosis is important if specific antibiotic treatment is to be effective. Data from trials of penicillin are contradictory, and direct comparisons are difficult because the definition of severe leptospirosis differs between studies $[14,15]$. Early treatment of 
acute anicteric leptospirosis with doxycycline reportedly aborts the disease [16]. All trials have demonstrated that treatment with penicillin or doxycycline shortens the duration of urinary excretion of leptospires.

One trial suggests that prophylaxis with doxycycline $200 \mathrm{mg}$ once weekly is effective in preventing infection in those likely to be exposed [17]. Given the large numbers of flood-related cases in Central American countries, there is an urgent need for larger, controlled trials of this simple approach to prevention [18].

Prevention of leptospirosis depends upon a twopronged strategy: firstly, exposure reduction (by better drainage, control of maintenance hosts and personal protective measures); and secondly, immunisation. Vaccines are widely used in domestic animals to prevent abortion and milk drop, and they have largely controlled infection with serovar canicola in dogs. Human vaccines are not widely used in Western countries. However, in China, Korea and Japan, polyvalent vaccines have been used extensively. Human vaccines are also used in Russia and Argentina. A vaccine containing only serovar icterohaemorrhagiae is licensed for human use in France, while a trivalent vaccine is undergoing clinical trials in Cuba (Dr Esther Fajardo, personal communication).

Leptospirosis has been recognised for $>100$ years. During that period the epidemiology has been elucidated and behaviour has been modified to reduce the risk of acquiring infection in many situations. However, most of those at risk of exposure live in poor, developing regions of the world. Vaccines are unlikely to be a widely available solution to this problem and only continued public health education efforts are likely to be effective in the long-term.

P. N. LEVETT

University of the West Indies,

School of Clinical Medicine and Research, Barbados and Leptospira Laboratory, Ministry of Health and the Environment, Barbados (e-mail: levett@sunbeach.net)

\section{References}

1. Bounlu $\mathrm{K}$, Insisiengmay $\mathrm{S}$, Vanthanouvong $\mathrm{K}$ et al. Acute jaundice in Vientiane, Lao People's Democratic Republic. Clin Infect Dis 1998; 27: 717-721.

2. Brandling-Bennett $\mathrm{AD}$, Pinheiro $\mathrm{F}$. Infectious diseases in Latin America and the Caribbean: are they really emerging and increasing? Emerg Infect Dis 1996; 2: 59-61.

3. Trevejo RT, Rigau-Perez JG, Ashford DA et al. Epidemic leptospirosis associated with pulmonary hemorrhage - Nicaragua, 1995. J Infect Dis 1998; 178: 1457-1463.

4. Chu KM, Rathinam $R$, Namperumalsamy $P$, Dean $D$. Identification of Leptospira species in the pathogenesis of uveitis and determination of clinical ocular characteristics in South India. J Infect Dis 1998; 177: 1314-1321.

5. Vinetz JM, Glass GE, Flexner CE, Mueller P, Kaslow DC. Sporadic urban leptospirosis. Ann Intern Med 1996; 125: 794-798.

6. Centers for Disease Control and Prevention. Update: leptospirosis and unexplained acute febrile illness among athletes participating in triathlons - Illinois and Wisconsin, 1998. MMWR Morb Mortal Wkly Rep 1998; 47: 673-676.

7. van Crevel R, Speelman P, Gravekamp C, Terpstra WJ. Leptospirosis in travelers. Clin Infect Dis 1994; 19: 132-134.

8. Reisberg BE, Wurtz R, Diaz $\mathrm{P}$ et al. Outbreak of leptospirosis among white-water rafters - Costa Rica, 1996. MMWR Morb Mortal Wkly Rep 1997; 46: 577-579.

9. Heron LG, Reiss-Levy EA, Jacques TC, Dickeson DJ, Smythe LD, Sorrell TC. Leptospirosis presenting as a haemorrhagic fever in a traveller from Africa. Med J Austral 1997; 167: 477-479.

10. Feresu SB, Bolin CA, Korver H. A new leptospiral serovar, ngavi, in the Tarassovi serogroup isolated from Zimbabwe oxen. Int J Syst Bacteriol 1998; 48: 207-213.

11. Romero EC, Caly CR, Yasuda PH. The persistence of leptospiral agglutinins titers in human sera diagnosed by the microscopic agglutination test. Rev Inst Med Trop São Paulo 1998; 40: 183-184.

12. Brown PD, Gravekamp C, Carrington DG et al. Evaluation of the polymerase chain reaction for early diagnosis of leptospirosis. J Med Microbiol 1995; 43: 110-114.

13. Zaki SR, Shieh W-J and the Epidemic Working Group at Ministry of Health in Nicaragua, Pan American Health Organisation, US Department of Agriculture, and Centers for Disease Control and Prevention. Leptospirosis associated with outbreak of acute febrile illness and pulmonary haemorrhage, Nicaragua, 1995. Lancet 1996; 347: 535.

14. Edwards CN, Nicholson GD, Hassell TA, Everard COR, Callender J. Penicillin therapy in icteric leptospirosis. $A m J$ Trop Med Hyg 1988; 39: 388-390.

15. Watt G, Padre LP, Tuazon ML et al. Placebo-controlled trial of intravenous penicillin for severe and late leptospirosis. Lancet 1988; 1: 433-435.

16. McClain JBL, Ballou WR, Harrison SM, Steinweg DL. Doxycycline therapy for leptospirosis. Ann Intern Med 1984; 100: $696-698$

17. Takafuji ET, Kirkpatrick JW, Miller RN et al. An efficacy trial of doxycycline chemoprophylaxis against leptospirosis. $N$ Engl $J$ Med 1984; 310: 497-500.

18. Gonsalez CR, Casseb J, Monteiro FG et al. Use of doxycycline for leptospirosis after high-risk exposure in Sao Paulo, Brazil. Rev Inst Med Trop São Paulo 1998; 41: 59-61.

\section{Summer Meeting of the \\ Pathological Society of Great Britain and Ireland University of Dundee, 7-9 July 1999}

The Microbiology Division has arranged two symposia; one (in conjunction with the Society for Anaerobic Microbiology) is entitled 'Clostridium Infections of Man and Animals' and the following speakers have agreed to contribute: Professor S. P. Borriello (London), Professor E. Stackebrandt (Braunschweig, Germany), Dr R. Titball (Salisbury), Professor D. Gerding (Chicago), Dr T. Netherwood (Newcastle), Dr L. C. Hunter (Edinburgh), Ms T. Ekong (London), Dr M. Brett (London). A half day Symposium on 'Microbial Host Interactions in the Gut' with Dr G. MacFarlane (Cambridge), Professor C. Dorman (Dublin), Professor M. Kerr (Dundee), Dr J. Crabtree (Leeds) and Dr J. Ketley (Leicester) as speakers has also been arranged. 